\title{
Local and Universal Action: The Paradoxes of Indole Signalling in
}

\section{Bacteria}

Ashraf Zarkan ${ }^{1, *}$, Junyan Liu², Marta Matuszewska ${ }^{3}$, Hannah Gaimster ${ }^{4}$, and David K. Summers ${ }^{1}$

${ }^{1}$ Department of Genetics, University of Cambridge, Cambridge, CB2 3EH, UK

${ }^{2}$ Wellcome Sanger Institute, Wellcome Genome Campus, Cambridge, CB10 1SA, UK

${ }^{3}$ Department of Veterinary Medicine, University of Cambridge, Cambridge, CB3 0ES, UK

${ }^{4}$ Institute of Cell \& Molecular Biosciences, Medical School, Newcastle University, Newcastle upon Tyne, NE2 4HH, UK

*Correspondence: maa77@cam.ac.uk (A. Zarkan)

Keywords : Indole signalling, Bacterial Membrane, Persisters, Cytoplasmic pH, Stress Response, Antibiotics 


\section{Highlights:}

- The role of indole in a wide range of stress responses is explored and explanations for the lack of consistency in the scientific literature are discussed.

- In view of the absence of a defined indole receptor protein, we discuss a proposal that the cell membrane is the primary target. The accumulation of indole in cell membranes, as well as its ability to pass thorough membranes in the absence of a protein transporter, offer explanations for its promiscuous effects on bacteria and eukaryotic cells.

- Indole signalling is exerted through one of two modes: a long lasting but low-level (persistent) signal or a transient, high-level (pulse) signal. Persistent signalling mediates resistance to multiple stresses including persister and biofilm formation while pulse signalling has been shown to contribute to $E$. coli survival under starvation and the regulation of cytoplasmic $\mathrm{pH}$.

\section{Abstract:}

Indole is a signalling molecule produced by many bacterial species and involved in intra-species, inter-species and inter-kingdom signalling. Despite the increasing volume of research published in this area, many aspects of indole signalling remain enigmatic. There is disagreement over the mechanism of indole import and export, and no clearly-defined target through which its effects are exerted. Progress is hindered further by the confused and sometimes contradictory body of indole research literature. We explore the reasons behind this lack of consistency and speculate whether the discovery of a new, pulse mode of indole signalling, together with a move away from the idea of a conventional protein target, might help to overcome these problems and enable the field to move forward. 


\section{Indole, a ubiquitous yet enigmatic signalling molecule}

Bacteria produce and sense a wide variety of small molecules for inter- and intracellular communication [1]. They use these chemical messages to respond optimally to physical and biological changes in the environment. Intercellular communication requires extracellular signals that may exert their effects on the producer organism itself, on other bacteria of the same species (intra-species signalling), or on bacteria of different species (inter-species signalling). In some cases, extra-cellular signals are also involved in interkingdom signalling between bacteria and their eukaryotic hosts.

Indole is an example of a signalling molecule involved in all of these scenarios [2,3]. A heterocyclic aromatic compound [4], it is produced in bacteria by the tetrameric enzyme tryptophanase (TnaA) that catalyses the conversion of tryptophan to indole, pyruvate and ammonia [5,6]. Over 85 bacteria are known to produce indole [7] and the list includes Gram-negative, Gram-positive, pathogenic and non-pathogenic species.

Indole displays a diverse range of effects on bacterial physiology and metabolism $[7,8]$, yet its molecular targets and mechanisms of action remain obscure. Thus, while there is general agreement that indole affects responses to stressors such as antibiotics, abnormal $\mathrm{pH}$, heat and reactive oxygen species, there is disagreement on whether responses to stressors such as the establishment of biofilms or the formation of bacterial persisters are enhanced or supressed by indole. Furthermore, there is no consensus on fundamental questions such as how indole is transported across the cell membrane and what is its primary target in the cell. In this review we explore these disputed territories and discuss the main gaps in our understanding of indole signalling. In seeking ways forward, we ask how recent advances, including the discovery of alternative signalling modes and the effect of indole on cell membranes, may lead to a more complete understanding of this complex topic.

\section{Indole transport across cell membranes}

One of the most fundamental yet controversial questions about indole signalling is how the signal crosses the cytoplasmic membrane. Despite a report fifty years ago that indole can diffuse through a lipid membrane [9], it is still often asserted that proteins such as Mtr and AcrEF play important transport roles. Mtr was identified originally as a tryptophan 
transporter [10], and the suggestion that it also imports indole came from indirect but elegant genetic experiments in the Yanofsky laboratory. An E. coli strain deficient in tryptophan biosynthesis (Trp-) could not grow on tryptophan-free medium. However, it was rescued by adding indole to the growth medium, as long as the tryptophanase operon (Figure 1) was induced by a non-metabolised inducer. When the Mtr gene was knockedout, rescue no longer occurred. It was proposed that indole restored growth because it was transported into the cell by Mtr where it was converted to tryptophan by tryptophanase in a reversal of the indole synthesis reaction [11]. When the work was replicated in another laboratory, Trp cells lacking Mtr did grow slowly on indole-containing medium. In an attempt to explain the lack of consistency between the two laboratories, the authors of the latter study proposed that the slow growth of the Trp- Mtr strain on indole-containing medium was evidence of slow indole uptake by passive diffusion or lower-affinity transporters in the absence of the main indole transporter, Mtr [12]. Further evidence for the role of passive diffusion in indole uptake is discussed below.

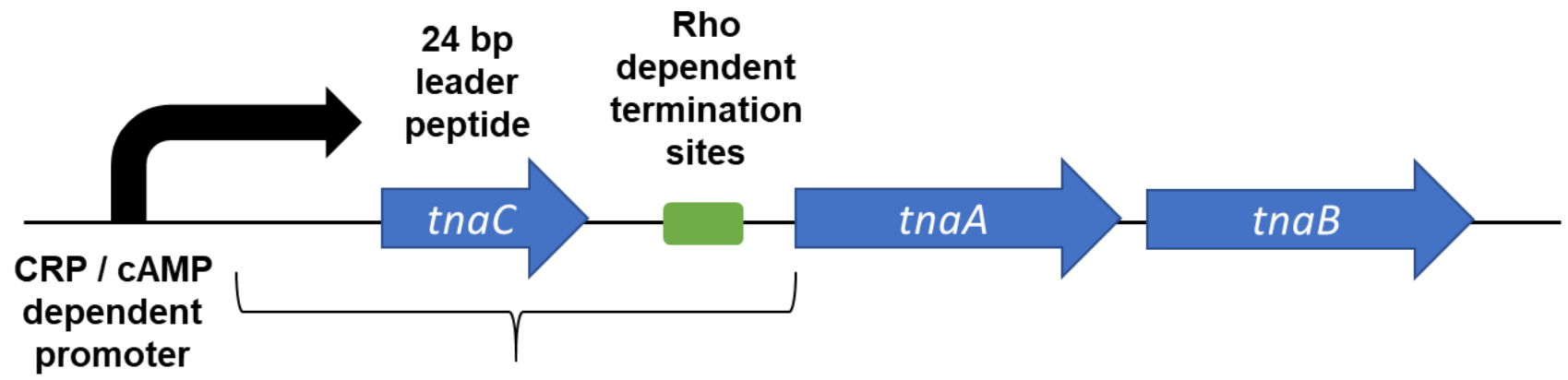

320 bp regulatory region

Figure 1: The tryptophanase operon in E. coli.

The operon consists of a CRP/cAMP-dependent promoter, a 320 bp regulatory region (transcription initiation site, tnaC \& Rho-dependent termination sites) and genes encoding tryptophanase $(\operatorname{tn} a A)$ and tryptophan specific permease $(\operatorname{tn} a B)$. Note: not drawn to scale. Figure based on references [13,14]. 
The search for an indole exporter started with an assumption that blocking export should increase the intracellular indole concentration, while simultaneously decreasing extracellular indole. An E. coli mutant lacking the AcrEF multidrug exporter ( $\triangle a c r E F)$ appeared to show this phenotype [15]. However, the conclusion that AcrEF is an indole exporter should be treated with caution. Firstly, the "indole excretion" assay used in this work in fact measured the total indole concentration (i.e. indole both inside the cells and in the growth medium; see Box 1). This total indole concentration should remain constant, irrespective of alterations in transport. The observed decrease in total indole for the $\triangle a c r E F$ mutant [15] therefore seems more likely to indicate decreased indole production, rather than decreased export. Secondly, the reported increase in intracellular indole in the $\triangle a c r E F$ strain was small (1.6-fold from a very low basal level). Unfortunately, the authors give no indication of the number of replicates they performed, nor do they estimate the error introduced into their measurements by washing the cells before conducting the assay (see Box 1).

In parallel with the publication of evidence supporting protein-mediated indole transport, other studies have concluded that indole does not require protein transporters to pass through a lipid membrane. One investigation used plasmid-based expression of styrene mono-oxygenase to convert intracellular indole to indigo. Exogenous indole was added to a culture of indole non-producing $(\Delta t n a A)$ cells and the rate of intracellular indigo accumulation was used to estimate the rate of indole uptake. The uptake rate was found to be independent of the presence of the putative importer Mtr [16]. The same report showed that the cell membrane is permeable to indole by demonstrating indole movement into protein-free vesicles made from E. coli lipid extract. A separate study, focussed on the biochemical properties of indole, concluded that indole displays high membrane permeability and can diffuse freely through cell membranes [17].

A possible resolution of these contradictions is that, in vivo, indole passes not only through lipid membranes but also via protein transporters,. However, evidence for high membrane permeability makes it difficult to see how indole concentrations inside or outside the cell could be regulated efficiently by modulating the activity of protein transporters. Nevertheless, it is by no means impossible and, if the debate is to be resolved, the onus is on supporters of protein-mediated indole transport to provide direct evidence for their hypothesis 


\section{Box 1: The perils of indole assays.}

A variety of assays, including chromatographic approaches [18] have been used to measure indole in bacterial culture. Most often, Kovac's reagent is used but experimental approaches vary, and consistent assay design is essential to ensure comparability of results from different laboratories. The use of analytical instruments such as mass spectrometry to measure indole has been described [18] but Kovac's remains the most widely used approach. Some experimenters add Kovac's directly to samples of bacterial culture [15]. Since the reagent lyses cells, this approach makes no distinction between indole dissolved in the growth medium and indole associated with the cells. In contrast, other experimenters first remove cells from the culture by centrifugation and so measure only the extra-cellular indole in the supernatant [19]. Some attempts have been made to estimate intra-cellular or cell-associated indole [15] but the permeability of lipid membranes to indole $[9,16]$ means that a substantial error will almost inevitably be introduced if the cell pellet is washed. An alternative approach is to omit the washing step and make a correction for the amount of supernatant indole trapped in the unwashed cell pellet [19].

When interpreting the results of indole assays, it is important to remember that even when extra-cellular and cell-associated indole are at equilibrium, they will be at very different concentrations. This is because the lipid-to-water partition coefficient for indole is approx. 100 [19], so indole partitions selectively into a non-polar environment. Consequently, in a bacterial culture, indole shows greater affinity for cells than for the culture medium. Furthermore, the concentration within the cells is non-uniform since indole shows a preference for lipid membranes over the cytoplasm. It has been determined experimentally that when indole is in equilibrium between cells and the culture medium, the cell-associated indole concentration (i.e. the concentration of indole in the cell pellet) is approx. 16-fold greater than the indole concentration in the growth medium [19]. However, in a non-equilibrium situation such as during the pulse of indole synthesis that occurs during the transition from exponential to stationary phase the cell-associated concentration can exceed the culture medium by up to 80 -fold.

\section{Indole and antibiotic persisters}

The addition of 4-5 mM indole to E. coli growing exponentially in broth culture arrests growth $[20,21]$. The cells remain viable and indole removal is followed by a resumption of growth. In an interesting parallel, reversible dormancy has increasingly been recognised as a natural strategy for antibiotic survival, and bacteria that avoid killing by this mechanism are known as persisters [22]. Persistence is seen for only a small sub-population of cells in a culture $(<1 \%)$ and is a physiological, rather than a genetic, state. The descendants of persisters that resume growth after antibiotic removal display the same antibiotic sensitivity as the original population. [23]. 
Unsurprisingly, the ability of indole to switch cells into a dormant state has attracted the attention of researchers seeking a plausible mechanism of persister cell establishment. However, these investigations have produced conflicting evidence. Some have found that indole stimulates $E$. coli persister formation at physiological concentrations [12, 24] while others [25] have come to the opposite conclusion, finding that reducing indole stimulates persister formation.

It is entirely possible that the role of indole in persister generation is variable across different antibiotics, different bacterial species and even different strains within the same species. When attempting to rationalise this conflict, it is important to remember that these studies have used diverse experimental approaches. Hu et al. [25] exposed exponential and stationary phase indole-negative $(\triangle \operatorname{tna} A) E$. coli to $0-2 \mathrm{mM}$ indole for $2 \mathrm{~h}$ before antibiotic treatment. Vega et al. [12] compared stationary-phase indole-negative $(\Delta t n a A)$ and wild-type cultures, and also supplemented an exponentially growing wild-type culture with $500 \mu \mathrm{M}$ indole. Kuczynska-Wisnik et al. [24] added 0-0.2 mM indole exogenously to stationary phase wild-type cells in LB medium. In the studies of Kuczynska-Wisnik et al. and Vega et al., where wild-type cells are used, it is difficult to quantify the indole responsible for the observed effects since no account seems to be taken of endogenously-produced indole.

The lack of consensus over the effect of indole on persister frequency may also be explained by the use of different antibiotics in the various studies (Table 1). Some studies use ofloxacin, a DNA gyrase inhibitor that targets both growing and non-growing cells, while others use ampicillin, a cell wall synthesis inhibitor that kills only actively growing cells. It is becoming clear that the persistent state cannot simply be equated with dormancy [26]. Persistent cells may need to enter different physiological states to survive the stresses imposed by antibiotics with different modes of action and these states might well be achieved via different mechanisms [27]. There is an urgent need for a comprehensive study, comparing the role of indole signalling in persister formation for different antibiotic classes under consistent experimental conditions. 
Table 1: How variable experimental design causes persistent confusion.

Cases where indole enhances persister formation

\begin{tabular}{|c|c|c|c|}
\hline Antibiotic & Indole added & Method \& Outcome & Ref \\
\hline $\begin{array}{l}\text { Ofloxacin }(5 \mu \mathrm{g} / \mathrm{mL}) \\
\text { Ampicillin }(100 \mu \mathrm{g} / \mathrm{mL}) \\
\text { Kanamycin }(10 \mu \mathrm{g} / \mathrm{mL})\end{array}$ & $0.5 \mathrm{mM}$ & $\begin{array}{l}\text { Indole addition to wild-type } E \text {. coli increased } \\
\text { persister by } 10 \text {-fold. } \\
\text { An indole non-producing } E \text {. coli mutant } \\
(\Delta t n a A) \text { had } 10 \text {-fold fewer persisters, which } \\
\text { was rescued by indole addition. }\end{array}$ & [12] \\
\hline Ofloxacin $(5 \mu \mathrm{g} / \mathrm{mL})$ & $\begin{array}{l}0.05 \mathrm{mM} \\
0.1 \mathrm{mM} \\
0.2 \mathrm{mM}\end{array}$ & $\begin{array}{l}\text { Indole addition to wild-type E. coli increased } \\
\text { persister formation: two-fold increase for } 0.1 \\
\mathrm{mM} \text { indole \& } 3 \text {-fold increase for } 0.2 \mathrm{mM} \\
\text { indole. }\end{array}$ & [24] \\
\hline
\end{tabular}

\section{Cases where indole decreases persister formation}

\begin{tabular}{|l|l|l|l|}
\hline Antibiotic & Indole added & $\begin{array}{l}\text { Method \& Outcome } \\
\text { An indole non-producing E. coli mutant } \\
(\Delta t n a A) \text { had 10-fold more persisters than } \\
\text { wild-type E. coli }\end{array}$ & Ref \\
\hline Ampicillin $(100 \mu \mathrm{g} / \mathrm{mL})$ & None & $\begin{array}{l}\text { Incubating an indole non-producing E. coli } \\
\text { mutant }(\Delta t n a A) \text { with indole for } 2 \text { h before } \\
\text { antibiotic treatment decreased persister } \\
\text { frequency (the higher the indole } \\
\text { concentration, the fewer the persisters). }\end{array}$ & [25] \\
\hline $\begin{array}{l}\text { Ampicillin }(100 \mu \mathrm{g} / \mathrm{mL}) \\
\text { Ciprofloxacin }(5 \mu \mathrm{g} / \mathrm{mL})\end{array}$ & $\begin{array}{l}0.5 \mathrm{mM} \\
1 \mathrm{mM} \\
2 \mathrm{mM}\end{array}$ & $\begin{array}{l}\text { Indole addition to wild-type E. coli decreased } \\
\text { persisters by } 75 \% .\end{array}$ & {$[28]$} \\
\hline Rifampicin $(100 \mu \mathrm{g} / \mathrm{mL})$ & $2 \mathrm{mM}$ & &
\end{tabular}

\section{The role of indole in biofilm formation}

Biofilms are bacterial populations in which cells embedded in a secreted matrix adhere to each other and to surfaces or interfaces. They show high tolerance to the host immune system and cause persistent infections that are resistant to treatment with antibiotics [29]. Up to $80 \%$ of bacterial infections in human patients are biofilm associated; such infections are caused mainly by Staphylococcus epidermidis, Pseudomonas aeruginosa, Staphylococcus aureus and Enterobacteria such as E. coli [29]. An effect of indole on biofilm formation has been reported for a wide range of indole-producing and non-producing strains, but there is no consensus on the direction of the effect [2] (Figure 2, Key Figure). 


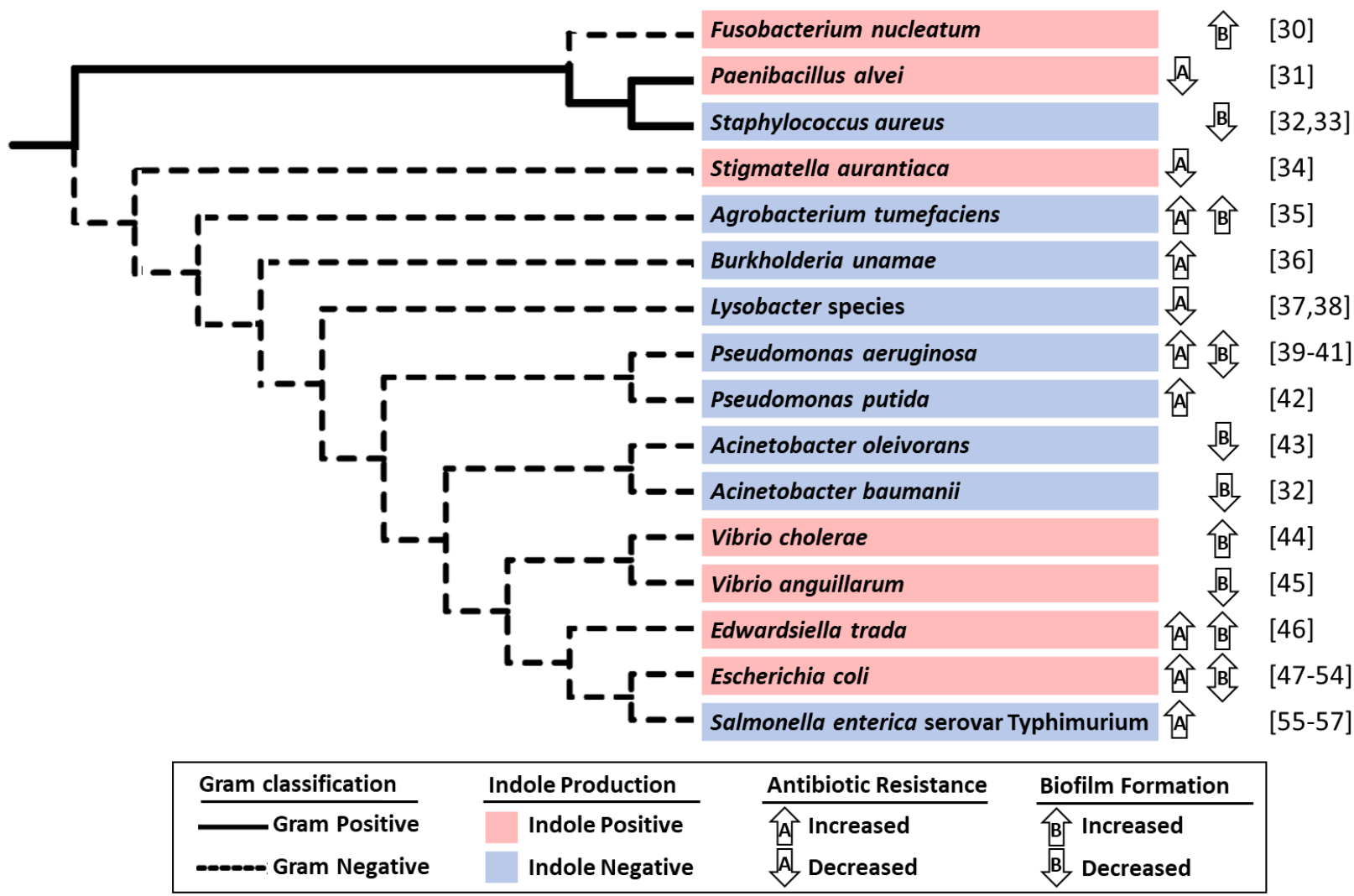

Figure 2: A cladogram of bacterial strains used in studies of the effect of indole on biofilm formation and antibiotic resistance.

The effect of indole is highly variable with no clear correlation with evolutionary relationships, Gram classification or indole production. The cladogram is derived from [58] (Details on the production of the cladogram are available as supplementary information). 
Confusion over indole modulation of bacterial biofilms is illustrated by studies on two clinically relevant strains, $E$. coli and $P$. aeruginosa. In $E$. coli (an indole producer), biofilm formation was reported initially to be inhibited by indole, via stress response and stationary phase regulatory pathways $[2,50,51]$. However, it was also reported that an indole-negative mutant of $E$. coli, and a wild-type strain treated with a chemical inhibitor of tryptophanase, displayed decreased biofilm formation compared to wild-type. Adding indole to the cultures restored their biofilm formation capacity $[48,49]$. $P$. aeruginosa cannot synthesise indole but biofilm formation was nevertheless enhanced by indole and 7-hydroxyindole [39], although it was inhibited by 2-aminobenzimidazole [40]. It has been suggested that the effect of indole on biofilm formation is concentration-dependant and strain specific [2] and it seems likely that this might be the source of the discrepancies in the data for $E$. coli and $P$. aeruginosa.

\section{Indole signalling and antibiotic resistance}

Indole has been shown to modulate resistance and tolerance to antibiotics in both indoleproducing and non-producing bacteria (Figure 2). Resistance increases the minimum inhibitory concentration (MIC) of the antibiotic, while tolerance increases the minimum duration for killing (MDK) [23]. Studies have been focussed mainly on Gram-negative species, where indole is often found to increase antibiotic resistance and tolerance via the activation of efflux pumps and induction of oxidative stress responses [35, 39, 46, 52-57]. However, two studies reported that indole decreases antibiotic resistance in the Gramnegative Lysobacter species by stimulating the vitamin $\mathrm{B}_{12}$ importer BtuD $[37,38]$. The weak selectivity of the importer causes cells to increase antibiotic uptake, resulting in cell death [38]. In contrast to the extensive work on antibiotic resistance of Gram-negative bacteria, studies on Gram-positive bacteria are few and are mainly limited to reports that indole decreases the formation of antibiotic-resistant spores by a poorly understood mechanism $[31,34]$.

Again, the lack of a consistent message in the literature may be explained by the choice of different bacterial strains or the different modes of action of the antibiotics used. It is also important to note that studies in most areas of indole action have been limited to persistent signalling. The effect of indole pulse signalling on biofilms, persister formation or antibiotic resistance remains unknown (Box 2). 


\section{Box 2: Pulse and persistent; alternative modes of indole signalling}

An LB culture of $E$. coli grown into stationary phase accumulates approx. $0.5 \mathrm{mM}$ indole in the growth medium. Reports of indole concentrations in human stool samples vary, but the mean is around 2.6 mM [59]. Hence indole concentrations in the range $0.5-2.5 \mathrm{mM}$ are often described as physiologically relevant and are used experimentally as medium supplements. The discovery of a new signalling mode, termed indole pulse signalling, has called into question this simple view of physiological relevance. In LB culture, E. coli makes the majority of its indole during stationary phase entry. Cell-associated indole rises dramatically over approx. $20 \mathrm{~min}$, peaking at approximately $60 \mathrm{mM}$ [19]. A plausible explanation for this high, transient concentration is that during this period indole is synthesised faster than it can exit the cell by diffusion or via membrane transporters. Attempts to reproduce the indole pulse experimentally have been made by adding 4-5 $\mathrm{mM}$ indole to the culture medium, then resuspending the cells in indole-free medium after 20 min [60]. To distinguish between the long-lasting and transient modes of indole signalling we refer to them as pulse and persistent. When considering their effects, one key distinction is that persistent signalling is the result of indole in the growth medium and hence is experienced equally by the producer cell and any other cells (producers or non-producers) in the same environment. Pulse signalling, on the other hand, is not experienced by indole non-producing cells. It is experienced exclusively by the producer cell and only during the period of rapid indole synthesis.

\section{The role of indole in acid and heat resistance}

Optimum growth and survival of $E$. coli occurs close to neutral $\mathrm{pH}$. A study by Hirakawa et al. found that indole increased survival when $E$. coli was exposed to acid stress at $\mathrm{pH} 3.5$ [53]. They showed that pre-incubation of E. coli with 1-2 mM indole increased the expression of acid resistance genes of the glutamine decarboxylase system, which in turn increased acid resistance. However, in apparent contradiction, $2 \mathrm{mM}$ indole added to a culture of $E$. coli during stress at $\mathrm{pH} 2.5$ was found to reduce survival significantly [47]. Once again, the contrasting outcomes may be explained by differences in the experimental design, with indole being present before the stress in one case but only during the stress in the other. Furthermore, the discrepancy in $\mathrm{pH}$ values used to stress the cells corresponds to a ten-fold difference in acid strength which may also have had an influence on the outcome.

The ability of $E$. coli to survive at high temperatures is an important challenge in the food industry [61]. A link with indole was established when $E$. coli was reported to show elevated indole production at $50^{\circ} \mathrm{C}$ [62]. The authors hypothesised that indole might 
increase survival at high temperatures but provided no evidence to support this. However, subsequent work showed that a low concentration of indole $(20 \mu \mathrm{M})$ added to a culture of indole non-producing cells ( $\left(\mathrm{TnA}^{-}\right)$stressed at $50^{\circ} \mathrm{C}$ does increase the proportion of survivors after 24h [63]. Interestingly, this latter study suggested that elevated indole production at $50^{\circ} \mathrm{C}$ [62] might not be a direct response to heat stress. It was noted that incubation of an $\mathrm{E}$. coli culture at $50^{\circ} \mathrm{C}$ arrests growth, and growth arrest has been found to stimulate indole production, whether it is due to heat stress, antibiotic treatment or the removal of nutrients [63].

Apart from acid and heat stress, indole was shown to increase $E$. coli survival during exposure to rhodamine $6 G$ and sodium dodecyl sulphate [64]. More recently, indole was proposed to be an important modulator in a complex stress response of cells in aging colonies [65]. Indole increased genetic diversity in these ageing colonies, resulting in the formation of clusters of cells characterised by unique phenotypes in comparison to their neighbours [65]. Perhaps unexpectedly, these authors found that indole production did not protect the aging cells from death but correlated with enhanced production of reactive oxygen species (ROS) and cell death. An element of kin selection was suggested by the authors who proposed that indole-mediated death of a proportion of cells might be providing nutrients for surviving neighbours. If indole production does indeed constitute a useful stress response, its mechanism of action is still far from being fully understood.

\section{Indole as an inter-species signal}

In an environment such as the human gut, bacteria are exposed to indole even when they do not themselves produce it. The diffusion of indole through a lipid membrane means that these non-producer cells inevitably experience indole in their cytoplasm and lipid membranes and this could potentially alter gene expression or other aspects of metabolism and physiology. The published literature suggests that inter-species effects of indole can be either beneficial or detrimental (Table 2). However, as in other areas, there is considerable variation in experimental approaches, as well as the test organism, so care is needed when making broad generalisations. 
Table 2: Indole as an inter-species signal: friend or foe?

\begin{tabular}{|c|c|c|c|}
\hline $\begin{array}{l}\text { Bacterial } \\
\text { recipient }\end{array}$ & $\begin{array}{l}\text { Indole } \\
\text { added }\end{array}$ & Method \& Outcome & Ref \\
\hline $\begin{array}{l}\text { Salmonella } \\
\text { typhimurium }\end{array}$ & $\begin{array}{l}2 \mathrm{mM} \\
7 \mathrm{~h}\end{array}$ & $\begin{array}{l}\text { Increased the expression of genes encoding the multidrug } \\
\text { exporters acr } A B \text {, emrAB, acr } D \text {, and } m d t A B C \text {. } \\
\text { Increased survival after exposure to benzalkonium. }\end{array}$ & [66] \\
\hline $\begin{array}{l}\text { Salmonella } \\
\text { typhimurium }\end{array}$ & $\begin{array}{l}0.5 \mathrm{mM} \\
1.25 \mathrm{mM}\end{array}$ & $\begin{array}{l}\text { Increased survival by } 3 \text {-fold after exposure to carbenicillin or } \\
\text { ciprofloxacin. }\end{array}$ & [55] \\
\hline $\begin{array}{l}\text { Salmonella } \\
\text { typhimurium }\end{array}$ & $\begin{array}{l}1 \mathrm{mM} \\
4 \mathrm{mM}\end{array}$ & $\begin{array}{l}\text { Up-regulated } 24 \text { genes with regulatory functions \& down- } \\
\text { regulation } 53 \text { genes involved in flagella biosynthesis and } \\
\text { chemotaxis. } \\
\text { Increased antibiotic tolerance via expression of efflux } \\
\text { pumps. }\end{array}$ & [57] \\
\hline $\begin{array}{l}\text { Pseudomonas } \\
\text { putida }\end{array}$ & $300 \mu \mathrm{M}$ & $\begin{array}{l}\text { Increased expression of the multidrug exporter pump } \\
\text { TtgGHI. } \\
\text { Increased the ability to grow in the presence of an inhibitory } \\
\text { level of ampicillin. }\end{array}$ & {$[42]$} \\
\hline
\end{tabular}

\section{Cases where the indole signal is detrimental to a bacterial recipient*}

\begin{tabular}{|c|c|c|c|}
\hline Antibiotic & $\begin{array}{l}\text { Indole } \\
\text { added }\end{array}$ & Method \& Outcome & Ref \\
\hline $\begin{array}{l}\text { Salmonella } \\
\text { typhimurium }\end{array}$ & $\begin{array}{l}1 \mathrm{mM} \\
24 \mathrm{~h}\end{array}$ & $\begin{array}{l}\text { Decreased motility and invasion of HeLa intestinal } \\
\text { epithelial cells and mouse macrophages. }\end{array}$ & [67] \\
\hline $\begin{array}{l}\text { Salmonella } \\
\text { enterica } \\
\text { serovar } \\
\text { Typhimurium }\end{array}$ & None & $\begin{array}{l}\text { Indole made by } E \text {. coli in the human gut reduced the } \\
\text { virulence of Salmonella enterica serovar Typhimurium, } \\
\text { thereby providing an advantage to } E \text {. coli as well as to the } \\
\text { human host. }\end{array}$ & {$[57]$} \\
\hline $\begin{array}{l}\text { Clostridium } \\
\text { difficile }\end{array}$ & None & $\begin{array}{l}\text { C. difficile induces the production of indole from } E \text {. coli in } \\
\text { the human gut, thereby inhibiting the growth of bacterial } \\
\text { species that compete with } C \text {. difficile, allowing the } \\
\text { pathogen to persist and recur } 1 \text { to } 4 \text { weeks after antibiotic } \\
\text { treatment. }\end{array}$ & [68] \\
\hline $\begin{array}{l}\text { Pseudomonas } \\
\text { putida }\end{array}$ & $\begin{array}{l}1 \mathrm{mM} \\
2 \mathrm{mM} \\
3 \mathrm{mM}\end{array}$ & $\begin{array}{l}1 \mathrm{mM} \text { altered expression of } 47 \text { genes, of which } 11 \text { are } \\
\text { involved in the tricarboxylic acid cycle and } 12 \text { function as } \\
\text { chaperones or proteases. } \\
2 \text { mM Reduced growth substantially. } \\
3 \text { mM caused complete growth inhibition. }\end{array}$ & [69] \\
\hline
\end{tabular}




\section{Choosing indole concentrations for experimental investigations}

We have suggested that the confusing and sometimes contradictory nature of much of the indole literature might be due to a lack of standardised experimental conditions in different laboratories. Indeed, it is impossible to describe one standard concentration at which indole signalling occurs. Most experimenters use LB medium and, under these conditions, there is huge variation in the production of indole during different phases of culture growth. Thus cells in lag and exponential phase experience a very low level of indole $(<0.05 \mathrm{mM})[63,70,71]$, and the main period of indole production occurs in late exponential and early stationary phase [20]. Levels of indole detected in stationary phase LB cultures vary depending on the measurement technique and the specific $E$. coli strain, but are typically $0.5-1 \mathrm{mM}[20,62,70,71]$. This corresponds closely to the concentration of free tryptophan in LB medium, which varies between $0.5 \mathrm{mM} \mathrm{[71]} \mathrm{and} 1 \mathrm{mM}$ [72]. Indeed, $E$. coli appears to convert to indole all free tryptophan remaining in the growth medium during stationary phase entry [71].

\section{Indole as stress response or stress insurance?}

As described previously, many researchers have explored the role of indole when bacteria are subjected to a range of stresses (temperature, $\mathrm{pH}$, antibiotics, etc). In studying these processes, it is important to distinguish indole production as a response to a specific stress, from pre-conditioning where indole makes cells better able to resist future, unknown stresses. Examples of both scenarios have been described in recent years.

There is no shortage of examples where indole production is a response to challenging conditions. A study of the effect of $\mathrm{pH}$ on indole production in $E$. coli reported that low $\mathrm{pH}$ inhibited indole production whilst high $\mathrm{pH}$ increased production both at $30^{\circ} \mathrm{C}$ and at $37^{\circ} \mathrm{C}$ [62]. This result was consistent with previous work showing that at $\mathrm{pH} 5$ expression of the tryptophanase gene was reduced, whilst at $\mathrm{pH} 9$ it was increased [73-75]. A response to antibiotic stress was seen where indole production per cell was increased by sub-inhibitory concentrations of ampicillin $\left(2 \mu \mathrm{g} \mathrm{mL}^{-1}\right)$ and kanamycin $\left(2 \mu \mathrm{g} \mathrm{mL}^{-1}\right)$ [62]. Also, under conditions of oxidative stress (elevated $\mathrm{H}_{2} \mathrm{O}_{2}$ and superoxide ion) caused by mutations or antibiotics [76], tryptophanase activity was up-regulated and the extracellular indole concentration increased accordingly [77]. It is tempting to speculate that there might be a single mechanism that links indole production to diverse stresses. Certainly, changes in 
temperature and $\mathrm{pH}$, and exposure to antibiotics and oxidative stress are likely to increase RpoS levels [78], which is known to induce tryptophanase expression and hence indole production [79]. However, this might not be the only mechanism. Many stresses also slow or arrest bacterial growth, and this alone has also been shown to stimulate indole synthesis [63].

Indole also plays a role pre-conditioning cells to resist future stresses. For wild-type $E$. coli in LB medium, an indole pulse at the end of exponential phase advances the transition into stationary phase, stopping growth before resources are exhausted [19]. When incubation of the stationary phase culture was continued in the same medium for a further ten days, wild-type cells showed much better survival than an indole non-producing mutant. The mutant displayed a short-term advantage over the wild-type, entering stationary phase at a higher cell density. However, this advantage was not maintained during the subsequent period of starvation, presumably because only the wild-type had set aside resources that could be used for survival and repair during the famine.

Recently, the indole pulse was shown to have a role regulating the cytoplasmic $\mathrm{pH}$ of E. coli [70]. This may also prove to be a form of pre-conditioning against stress but, as yet, there are no data to support this. Interestingly, maintenance of the correct cytoplasmic $\mathrm{pH}$ during exponential growth was dependent upon the indole pulse at the transition from the previous period of exponential growth into stationary phase. Thus, the cells retain some "memory" of the pulse even after being sub-cultured into fresh medium. The nature of this memory is unknown but one possibility is that the indole pulse could influence the distribution of membrane proteins, with the indole-dependent distribution serving as the memory repository [70].

\section{Quorum sensing or leaking metabolite; what is the true nature of the indole signal?}

The enigmatic nature of indole signalling is evidenced by the difficulty of pinning-down its mode of action. Several reports refer to indole as a quorum sensing molecule $[7,80,81]$ and it is true that the use of conditioned medium, or chemical complementation, has been effective in reproducing the induction of xenobiotic exporter genes $\operatorname{acr} D$, acrE, cusB and emrK [64]. However, for other genes including gabT, astD and tnaB, chemical complementation has failed to reproduce the full effect of natural indole production [82]. In mathematical models of quorum sensing, it is typically assumed that the autoinducer is Page | 15 
produced and secreted at a constant rate [83] but this is clearly not true for indole production [19]. Finally, the recent description of indole pulse signalling clearly places at least these aspects of indole action well outside the quorum sensing paradigm.

In an attempt to rationalise the field of bacterial cell signalling, Winzer et al listed qualifying attributes for cell-to-cell signalling molecules (CCSM) [84]. The objective was to distinguish true signalling molecules from non-signalling metabolites that accumulate in the culture supernatant. An aspiring CSSM must satisfy four criteria: (i) it must be made at a specific stage, (ii) it must accumulate externally and be recognised by a specific receptor, (iii) accumulation must generate a concerted response and (iv) the cellular response must extend beyond physiological changes that remove or detoxify the molecule. When indole was assessed against these key criteria, it was concluded that low levels of indole $(<1 \mathrm{mM})$ satisfy at least some of them [7]. Certainly, indole produced by cells growing in LB broth is made at a specific stage of growth and accumulates externally. Although a specific receptor remains hard to find, the lack of discovery does not mean it does not exist, especially considering that potential indole receptors have been described in mammalian cells, such as aryl hydrocarbon receptor (AHR) in the human gastrointestinal cells $[85,86]$. Also, the bacterial membrane-bound histidine sensor kinase (HK) CpxA has been recently proposed as an indole sensor [87]. Additionally, an almost overwhelming number of responses has been identified and these are certainly distinct from removal or detoxification of the signal. However, pulse signalling during stationary phase entry [19] confuses the argument once again. Here the accumulation of indole in the external medium is irrelevant, while the cellassociated (intracellular) concentration is crucial. Indeed, since pulse signalling is by necessity independent of cell density, it fails to meet the qualifying criteria for either quorum sensing or CCSM.

\section{A final puzzle: there is no clearly-defined target or mode of action for indole in the bacterial cell}

Unusually for a signalling molecule, indole has no clearly-defined protein receptor [8]. It has been reported that indole inhibits DNA gyrase in vitro [88], implying a direct interaction with this protein. However, significant inhibition of supercoiling activity only becomes apparent in the 2-5 $\mathrm{mM}$ range, suggesting that the indole-gyrase interaction is relatively weak. It has also been proposed that the effect of indole on biofilm formation is mediated 
via the quorum sensing regulator SdiA, possibly by direct binding [47]. However, subsequent studies have disputed this, suggesting that the effect is indirect and that higher concentrations of indole inhibit N-acyl-L-homoserine lactone sensing by SdiA [89].

Three envelope stress response modules (BaeSR, CpxAR and the phage shock pathway) respond to indole, suggesting that the cell membrane itself might be an important target $[12,60,90]$. Certainly, indole favours a lipid environment over aqueous solution. The lipid:aqueous partition coefficient for indole is approx. 100 [19], so stationary phase E. coli cells in LB would have an indole concentration of 50-100 mM in their membranes. In vitro, the incorporation of indole into a lipid bilayer has been shown to result in alteration of the activity of the bacterial tension-activated channel MscS [17], providing further evidence that membrane accumulation might be responsible for some effects of indole via modulation of membrane protein activity.

In addition to altering membrane tension, indole makes membranes permeable to protons in a dose-dependent manner [91]. This explains why 4-5 mM indole inhibits $E$. coli cell division in broth culture [20]. The loss of the proton gradient prevents MinCD oscillation, which disrupts the proper localisation of FtsZ, thus inhibiting cell division [21]. The recent discovery that the MinCD system is responsible for the distribution of a wide range of functionally-unrelated membrane proteins [92] raises the possibility that the same mechanism might underpin other indole responses. Finally, it is possible that by acting as a partial uncoupler, indole has effects on key processes including membrane transport and ATP synthesis, although these areas have not yet been explored.

\section{Concluding Remarks}

Indole signalling underpins an extraordinarily diverse field of study with major implications for bacterial communication and human health. It is unfortunate that such an important field is underwritten by a confusing and, sometimes, contradictory body of scientific literature. In this review we have discussed the major gaps and contradictions in the field and have attempted to understand how these problems have arisen. We conclude that in part difficulties arise from a lack of consistent approaches by the many groups working in the area. We also draw attention to the potential confusion caused by the existence of at least two very different modes of indole signalling (pulse and persistent) and 
underline the need to take their differences into account when assessing the effects of indole on cells producing and receiving the signal.

\section{Outstanding Questions}

- Indole has been shown to diffuse freely across lipid membrane but do specific indole transporters also play a role?

- What is the primary target of the indole signal? Should we move away from the concept of a conventional protein receptor and consider the membrane as the main organ of indole detection and response?

- Are the effects of indole on persister and biofilm formation, ageing in colonies and resistance to heat, acid and antibiotics due only to conventional (i.e. persistent) signalling? Could the involvement of pulse signalling explain some of the conflicting and contradictory results coming from different laboratories?

\section{Acknowledgements}

Ashraf Zarkan \& David Summers are grateful for funding from the Leverhulme Trust, UK (RPG-2015-184), Innovate UK: SBRI (971621) and Wellcome Trust Developing Concept Fund (RG93172). We thank Mr Cameron Croft (Department of Genetics, University of Cambridge) for helpful comments. We thank Dr Gemma Murray (Department of Veterinary Medicine, University of Cambridge) for help in generating the cladogram.

\section{References}

1. Bandara, H.M. et al. (2012) Microbial chemical signaling: a current perspective. Crit Rev Microbiol. 38, 217-249.

2. Lee, J.H. et al. (2015) Roles of indole as an interspecies and interkingdom signaling molecule. Trends Microbiol. 23, 707-718.

3. Tomberlin, J.K. et al. (2017) Indole: An evolutionarily conserved influencer of behavior across kingdoms. Bioessays. 39, 10.1002/bies.201600203.

4. Roychowdhury, P. and Basak, B.S. (1975) The crystal structure of indole. Acta Cryst. B3, 1559-1563.

5. Wood, W.A. et al. (1947) Function of Pyridoxal Phosphate: Resolution and Purification of the Tryptophanase Enzyme of Escherichia coli. J. Biol. Chem. 170, 313-321. 
6. Tewari, Y.B. and Goldberg, R.N. (1994) An equilibrium and calorimetric investigation of the hydrolysis of L-tryptophan to (indole + pyruvate + ammonia). J Solution Chem. 23, 167-184.

7. Lee, J.-H. and Lee, J. (2010) Indole as an intercellular signal in microbial communities. FEMS Microbiol Rev. 34, 426-444.

8. Kim, J. and Park, W. (2015) Indole: a signaling molecule or a mere metabolic byproduct that alters bacterial physiology at a high concentration?. J Microbiol. 53, 421-428.

9. Bean, R.C. et al. (1968) Permeability of lipid bilayer membranes to organic solutes. J Gen Physiol. 52, 495-508.

10. Heatwole, V.M. and Somerville, R.L. (1991) Cloning, nucleotide sequence, and characterization of $\mathrm{mtr}$, the structural gene for a tryptophan-specific permease of Escherichia coli K-12. J Bacteriol. 173, 108-115.

11. Yanofsky, C. et al. (1991) Physiological studies of tryptophan transport and tryptophanase operon induction in Escherichia coli. J Bacteriol. 173, 6009-6017.

12. Vega, N.M. et al. (2012) Signaling-mediated bacterial persister formation. Nat Chem Biol. 8, 431-433.

13. Deeley, M.C. and Yanofsky, C. (1982) Transcription initiation at the tryptophanase promoter of Escherichia coli K-12. J Bacteriol. 151, 942-951.

14. Stewart, V. and Yanofsky. C. (1985) Evidence for transcription antitermination control of tryptophanase operon expression in Escherichia coli K-12. J Bacteriol. 164, 731-740.

15. Kawamura-Sato, K. et al. (1999) Role of multiple efflux pumps in Escherichia coli in indole expulsion. FEMS Microbiol Lett. 179, 345-352.

16. Piñero-Fernandez, S. et al. (2011) Indole transport across Escherichia coli membranes. J Bacteriol. 193,1793-1798.

17. Kamaraju, K. et al. (2011) Effects on membrane lateral pressure suggest permeation mechanisms for bacterial quorum signaling molecules. Biochem. 50, 6983-6993.

18. Zhong, Q. et al. (2019) Profles of volatile indole emitted by Escherichia coli based on CDI-MS. Sci Rep. 9, 13139.

19. Gaimster, H. et al. (2014) The Indole Pulse: A New Perspective on Indole Signalling in Escherichia coli. PLoS One. 9, e93168.

20. Chant, E.L. and Summers, D.K. (2007) Indole signalling contributes to the stable maintenance of Escherichia coli multicopy plasmids. Mol Microbiol. 63, 35-43.

21. Chimerel, C. et al. (2012) Indole prevents Escherichia coli cell division by modulating membrane potential. Biochim Biophys Acta. 1818, 1590-1594.

22. Lewis, K. (2007) Persister cells, dormancy and infectious disease. Nat Rev Microbiol. 5, 48-56

23. Balaban, N.Q. et al. (2019) Definitions and guidelines for research on antibiotic persistence. Nat. Rev. Microbiol. 17, 441-448.

24. Kuczyńska-Wiśnik, D. et al. (2015) Lack of intracellular trehalose affects formation of Escherichia coli persister cells. Microbiol. 161,786-796.

25. Hu, Y. et al. (2015) Toxin YafQ increases persister cell formation by reducing indole signalling. Environ Microbiol. 17, 1275-1285.

26. Wilmaerts, D. et al. (2019). General Mechanisms Leading to Persister Formation and Awakening. Trends Genet. 35, 401-411.

27. Kwan, B.W. et al. (2015) Phosphodiesterase DosP increases persistence by reducing cAMP which reduces the signal indole. Biotechnol Bioeng. 112, 588-600.

28. Lee, J.H. et al. (2016) Halogenated indoles eradicate bacterial persister cells and biofilms. AMB Express. 6, 123.

29. Römling, U. and Balsalobre, C. (2012) Biofilm infections, their resilience to therapy and innovative treatment strategies. J. Intern. Med. 272, 541-561.

Page | 19 
30. Sasaki-Imamura, T. et al. 2010) Production of indole from L-tryptophan and effects of these compounds on biofilm formation by Fusobacterium nucleatum ATCC 25586. Appl Environ Microbiol. 76, 4260-4268.

31. Wang, Y. et al. (2019) Indole Reverses Intrinsic Antibiotic Resistance by Activating a Novel Dual-Function Importer. mBio. 10, e00676-19.

32. Bunders, C. et al. (2011) Flustramine inspired synthesis and biological evaluation of pyrroloindoline triazole amides as novel inhibitors of bacterial biofilms. Org. Biomol. Chem. 9, 5476-5481.

33. Bunders, C.A. et al. (2011) Intercepting bacterial indole signaling with flustramine derivatives. J. Am. Chem. Soc. 133, 20160-20163.

34. Stamm, I. et al. (2005) The pyruvate kinase of Stigmatella aurantiaca is an indole binding protein and essential for development. Mol. Microbiol. 56, 1386-1395.

35. Lee, J-.H. et al. (2015) The multifaceted roles of the interspecies signalling molecule indole in Agrobacterium tumefaciens. Environ. Microbiol. 17, 1234-1244.

36. Kim, D. et al. (2013) Induction of biofilm formation in the betaproteobacterium Burkholderia unamae CK43B exposed to exogenous indole and gallic acid. Appl. Environ. Microbiol. 79, 4845-4852.

37. Han, Y. et al. (2017) Indole-Induced Reversion of Intrinsic Multiantibiotic Resistance in Lysobacter enzymogenes. Appl Environ Microbiol. 83, e00995-17.

38. Wang, Y. et al. (2019) Indole Reverses Intrinsic Antibiotic Resistance by Activating a Novel Dual-Function Importer. mBio. 10, e00676-19.

39. Lee, J. et al.(2009) Indole and 7-hydroxyindole diminish Pseudomonas aeruginosa virulence. Microb Biotechnol. 2, 75-90.

40. Frei, R. et al. (2012) 2-Aminobenzimidazole derivatives strongly inhibit and disperse Pseudomonas aeruginosa biofilms. Angew. Chem. Int. Edit. 51, 5226-5229.

41. Lee, J-.H. et al. (2012) 7-Fluoroindole as an antivirulence compound against Pseudomonas aeruginosa. FEMS Microbiol. Lett. 329, 36-44.

42. Molina-Santiago, C. et al. (2014) Interspecies signalling: Pseudomonas putida efflux pump TtgGHI is activated by indole to increase antibiotic resistance. Environ Microbiol. 16,1267-1281.

43. Kim, J. and Park, W. (2013) Indole inhibits bacterial quorum sensing signal transmission by interfering with quorum sensing regulator folding. Microbiol. 159, 26162625.

44. Mueller, R.S. et al. (2009) Indole acts as an extracellular cue regulating gene expression in Vibrio cholerae. J Bacteriol. 191, 3504-3516.

45. Li, X. et al (2014). RpoS and indole signaling control the virulence of Vibrio anguillarum towards gnotobiotic sea bass (Dicentrarchus labrax) larvae. PLoS ONE. 9, e111801.

46. Han, Y. et al. (2011) Mutation of tryptophanase gene tnaA in Edwardsiella tarda reduces lipopolysaccharide production, antibiotic resistance and virulence. Environ. Microbiol. Rep. 3, 603-612.

47. Lee, J. et al. (2007) Indole is an inter-species biofilm signal mediated by SdiA. BMC Microbiol. 7, 42.

48. Martino, P. et al. (2002) Isolation of an Escherichia coli strain mutant unable to form biofilm on polystyrene and to adhere to human pneumocyte cells: involvement of tryptophanase. Can J Microbiol. 48, 132-137.

49. Martino, P.D. et al. (2003) Indole can act as an extracellular signal to regulate biofilm formation of Escherichia coli and other indole-producing bacteria. Can J Microbiol. 49, 443-449. 
50. Hu, M. et al. (2010) Indole Affects Biofilm Formation in Bacteria. Indian J Microbiol. 50, 362-368.

51. Ito, A. et al. (2008).Significance of rpoS during maturation of Escherichia coli biofilms. Biotechnol Bioeng. 99, 1462-1471.

52. Lee, H.H. et al. (2010) Bacterial charity work leads to population-wide resistance. Nature. 467, 82-85.

53. Hirakawa, H. et al. (2010) Indole enhances acid resistance in Escherichia coli. Microb Pathog. 49, 90-94.

54. Lee, J. et al. (2008) Indole cell signaling occurs primarily at low temperatures in Escherichia coli. ISME J. 2, 1007-1023.

55. Vega, N.M. et al. (2013) Salmonella typhimurium intercepts Escherichia coli signaling to enhance antibiotic tolerance. Proc Natl Acad Sci U S A. 110, 14420-14425.

56. Blair, J.M.A. et al. (2013) Alternative explanation for indole-induced antibiotic tolerance in Salmonella. Proc. Natl. Acad. Sci. U.S.A. 110, E4569.

57. Nikaido, E. et al. (2012) Effects of indole on drug resistance and virulence of Salmonella enterica serovar Typhimurium revealed by genome-wide analyses. Gut Pathog. 4, 5.

58. Wu, D. et al. (2009) A phylogeny-driven genomic encyclopaedia of Bacteria and Archaea. Nature. 462, 1056-1060.

59. Darkoh, C. et al. (2015) A rapid and specific method for the detection of indole in complex biological samples. Appl Environ Microbiol. 81, 8093-8097.

60. Raffa, R.G. and Raivio, T.L. (2002) A third envelope stress signal transduction pathway in Escherichia coli. Mol Microbiol. 45, 1599-1611.

61. Juneja, V.K. et al. (1997) Thermal destruction of Escherichia coli O157:H7 in beef and chicken: determination of D- and z-values. Int J Food Microbiol. 35, 231-237.

62. Han, T.H. et al. (2011) Environmental factors affecting indole production in Escherichia coli. Res Microbiol. 162, 108-116.

63. Liu, J, and Summers, D. (2017) Indole at low concentration helps exponentially growing Escherichia coli survive at high temperature. PLoS One. 12, e0188853.

64. Hirakawa, H. et al. (2005) Indole induces the expression of multidrug exporter genes in Escherichia coli. Mol Microbiol. 55, 1113-1126.

65. Saint-Ruf, C. et al. (2014) Massive diversification in aging colonies of Escherichia coli. $J$ Bacteriol. 196, 3059-3073.

66. Nikaido, E. et al. (2008) AcrAB multidrug efflux pump regulation in Salmonella enterica serovar Typhimurium by RamA in response to environmental signals. J Biol Chem. 283, 24245-24253.

67. Kohli, N. et al. (2018) The microbiota metabolite indole inhibits Salmonella virulence. Involvement of the PhoPQ two-component system. PLoS One. 13, e0190613.

68. Darkoh, C. et al. (2019) Clostridium difficile Modulates the Gut Microbiota by Inducing the Production of Indole, an Interkingdom Signaling and Antimicrobial Molecule. mSystems. 4, e00346-18.

69. Kim, J. et al. (2013) Indole toxicity involves the inhibition of adenosine triphosphate production and protein folding in Pseudomonas putida. FEMS Microbiol Lett. 343, 8999.

70. Zarkan, A. et al. (2019) Indole pulse signalling regulates the cytoplasmic $\mathrm{pH}$ of $E$. coli in a memory-like manner. Sci Rep. 9, 3868.

71. Li, G. and Young, K.D. (2013) Indole production by the tryptophanase TnaA in Escherichia coli is determined by the amount of exogenous tryptophan. Microbiol. 159, 402-410. 
72. Sezonov, G. et al. (2007) Escherichia coli physiology in Luria-Bertani broth. J Bacteriol. 189, 8746-8749.

73. Maurer, L. M. et al. (2005) pH regulates genes for flagellar motility, catabolism, and oxidative stress in Escherichia coli K-12. J Bacteriol. 187, 304-319.

74. Blankenhorn, D. et al. (1999) Acid- and base-induced proteins during aerobic and anaerobic growth of Escherichia coli revealed by two-dimensional gel electrophoresis. $J$ Bacteriol. 181, 2209-2216.

75. Stancik, L. M. et al. (2002) pH-dependent expression of periplasmic proteins and amino acid catabolism in Escherichia coli: J Bacteriol. 184, 4246-4258.

76. Kuczyńska-Wiśnik, D. et al. (2010) Antibiotics promoting oxidative stress inhibit formation of Escherichia coli biofilm via indole signalling. Res Microbiol. 161, 847-853.

77. Kuczyńska-Wiśnik, D. et al. (2010) Escherichia coli heat-shock proteins IbpA and IbpB affect biofilm formation by influencing the level of extracellular indole. Microbiol. 156, 148-157.

78. Battesti, A. et al. (2011) The RpoS-mediated general stress response in Escherichia coli. Annu Rev Microbiol. 65, 189-213.

79. Lacour, S. and Landini. P. (2004) SigmaS-dependent gene expression at the onset of stationary phase in Escherichia coli: function of sigmaS-dependent genes and identification of their promoter sequences. J Bacteriol. 186, 7186-7195.

80. Lee, J. et al. (2009) Reconfiguring the quorum-sensing regulator SdiA of Escherichia coli to control biofilm formation via indole and $\mathrm{N}$-acylhomoserine lactones. Appl Environ Microbiol. 75, 1703-1716.

81. Walters, M. and Sperandio, V. (2006) Quorum sensing in Escherichia coli and Salmonella. Int J Med Microbiol. 296, 125-131.

82. Wang, D. et al. (2001) Indole can act as an extracellular signal in Escherichia coli. J Bacteriol. 183, 4210-4216.

83. Nadell, C.D. et al. (2008) The evolution of quorum sensing in bacterial biofilms. PLoS Biol. 6, e14.

84. Winzer, K. et al. (2002) Bacterial cell-to-cell communication: sorry, can't talk now - gone to lunch!. Curr Opin Microbiol. 5, 216-222.

85. Hubbard, T.D. et al. (2015) Adaptation of the human aryl hydrocarbon receptor to sense microbiota-derived indoles. Sci Rep. 5, 12689.

86. Hubbard, T.D. et al. (2015) Indole and Tryptophan Metabolism: Endogenous and Dietary Routes to Ah Receptor Activation. Drug Metab Dispos. 43, 1522-1535.

87. Kumar, A. and Sperandio, V. (2019) Indole Signaling at the Host-Microbiota-Pathogen Interface. mBio. 10, e01031-19.

88. Field, C.M. and Summers, D.K. (2012) Indole inhibition of ColE1 replication contributes to stable plasmid maintenance. Plasmid. 67, 88-94.

89. Sabag-Daigle, A. et al. (2012) The acyl homoserine lactone receptor, SdiA, of Escherichia coli and Salmonella enterica serovar Typhimurium does not respond to indole. Appl Environ Microbiol. 78, 5424-5431.

90. Weatherspoon-Griffin, N. et al. (2014) The CpxR/CpxA two-component regulatory system up-regulates the multidrug resistance cascade to facilitate Escherichia coli resistance to a model antimicrobial peptide. J Biol Chem. 289, 32571-32582.

91. Chimerel, C. et al. (2013) The effect of bacterial signal indole on the electrical properties of lipid membranes. Chemphyschem. 14, 417-423.

92. Ramm, B. et al. (2018). The MinDE system is a generic spatial cue for membrane protein distribution in vitro. Nat Commun. 9, 3942. 